\title{
Salutogenesis: Sense of Coherence in Childhood and Families
}

\author{
Orly Idan, Orna Braun-Lewensohn, Bengt Lindström, \\ and Malka Margalit
}

\section{Introduction}

Infancy and early childhood are distinct developmental periods in which young children differ significantly from older children, adolescents, and adults in terms of cognitive skills, language and communication, self-regulation, and socioemotional functioning (Mowder et al., 2009). The science of early childhood development demonstrates that the foundations for sound mental health are built early in life, as early experiences shape the architecture of the developing brain (Miller \& Kinsbourne, 2012). These important experiences include children's relationships with parents, caregivers, relatives, teachers, and peers, which play a critical role in shaping social, emotional, and cognitive development. Recent research indicates that early intervention can have a positive impact on the trajectory of common emotional or behavioral problems as well as on outcomes for children with adversities and disorders (National Scientific Council on the Developing Child, 2012). Adverse experiences early in life, particularly for vulnerable children, have been shown to predict the emergence of later physical and mental health problems (Edwards

This chapter is a revision and update of work published in Mittelmark, M.B., Sagy, S., Eriksson, M., Bauer, G., Pelikan, J.M., Lindström, B., \& Espnes, G.A. (eds). (2017). The Handbook of Salutogenesis. Springer, Cham. DOI: https://doi.org/10.1007/978-3-319-04600-6.

O. Idan $(\bowtie)$

School of Psychology, Interdisciplinary Center (IDC), Herzliya, Israel

e-mail: oidan@idc.ac.il

O. Braun-Lewensohn

Conflict Management and Resolution Program, Ben-Gurion

University of the Negev, Beer Sheva, Israel

B. Lindström

NTNU Center for Health Promotion Research, Norwegian

University of Science and Technology, Trondheim, Norway

e-mail: bengtblind@ hotmail.com

M. Margalit

Tel Aviv University, and Peres Academic Center, Rehovot, Israel et al., 2003). Although mental health challenges for young children share many biological and behavioral characteristics with those of older children and adults, several aspects differentiate early childhood from later developmental stages. First, emotional health for young children is very strongly influenced by their environment and the nature of their relationships and the support or risks these relationships confer. Therefore, it is essential to examine the quality of the children's environments and relationships to tap the risks for adversaries and the protective factors that may assist in promoting mental and physical health. Second, cognitive, social, and emotional characteristics are all intertwined within the architecture of the brain, and these capacities vary at different developmental stages. Children understand, manage, think, feel, and talk about their experiences differently at different ages. These developmental differences are important to understanding the behavioral and emotional risks and protective factors involved. Finally, in early childhood, it can be challenging to distinguish temporary deviations in behavior from persistent problems, or typical differences in maturation from developmental delays (Rubin et al., 2006).

From birth, children develop their abilities to experience and express a diverse range of emotions, as well as their capacity to cope with and manage different feelings (Thompson \& Lagattuta, 2006). The development of these capabilities occurs at the same time as a wide range of highly visible skills in mobility, cognition, and communication (Thompson, 2001). The foundations of social competence that are developed in the first 5 years are linked to emotional well-being and affect a child's ability to functionally adapt in school later on and form promoting relationships during adolescence and adulthood (Cassidy \& Shaver, 1999). Therefore, it is important to address children's affective and cognitive aspects. Failure to address difficulties in the socioemotional domain may result in missed opportunities for interventions at critical periods (National Scientific Council on the Developing Child, 2004).

The emotional experiences of newborns and young infants occur for the most while interacting with their caregivers. 
Associations between positive emotions and the availability of responsive caregivers are strengthened during infancy in both behavior and brain architecture (Cassidy, 1994). Toddlers and preschool children depend on their emerging capacities to interpret their personal experiences and understand what others are doing and thinking, as well as to interpret the distinctions between different responses to them. By the end of the preschool years, children who have acquired emotional regulation skills can use their awareness of their own and others' feelings to interact daily (Thompson \& Lagattuta, 2006). Studies on preschool children have shown how the interrelated development of emotion and cognition relies on the emergence, maturation, and interconnection of complex neural circuits in multiple areas of the brain (Davidson et al., 2002). A large-scale study examining a biopsychosocial model of risk and resilience on behavior at preadolescence indicated the importance of biological and psychosocial factors, including the SOC, on resilient outcomes and preadolescents' mental health (Agnafors et al., 2017).

Thus, the emotional development of young children is correlated to the characteristics of the environments in which they live, including their families, school, and community (Reid et al., 2002). A Children's Sense of Coherence Scale (CSOC) based on the three components of the SOC construct was developed (Margalit \& Efrati, 1995).

\section{Children's Sense of Coherence Scale}

The Children's Sense of Coherence Scale (CSOC) (Margalit \& Efrati, 1995) is an adaptation of the Antonovsky Orientation to Life (Sense of Coherence-SOC) Scale (Antonovsky, 1987). In line with the sense of coherence construct and the adults' scale, a children's version (CSOC) was developed, field-tested, and revised several times at the Special Education Laboratory in Tel-Aviv University.

Due to the children's young age and reservations regarding the ability of children to comprehend the construct and scale, it was decided to develop a scale that would meet the unique characteristics of the target population. The scale was developed in collaboration with Aaron and Helen Antonovsky. The scale included distractors relating to the children's lives and activities. The CSOC's wording, the order of words, examples, and distracters were examined to ensure the comprehension of young children and the inclusion of ageappropriate content. Since its development, several new versions have been used, such as for junior high school students, omitting the distracter items, for example, "I'm interested in lots of things" and "I' $m$ interested in lots of things in my class" (for school-based research, or "at home"-for family-based research). In general, distractors were coherent with culture.
The children's scale was tested on children of age 5 to adolescents. Comprehension was examined using unstructured interviews; a series of retests verified stability. Conceptually, the items were derived from SOC-29 and the three components of the SOC. This consisted of 16 primary items and 3 filler items on a four-point Likert scale (the range was reduced to 4 from "never" (1) to "always" (4)). Scores ranged from 16 to 64, with items describing the children's feeling of confidence in their world, as expressed in their sense of comprehensibility - understanding their environment (i.e., "I feel that I don't know what to do in class"); sense of manageability-feelings of control, and confidence that when help is needed, it will be available (i.e., "when I want something, I'm sure I'll get it"); and meaningfulness interest in investing efforts in different tasks (i.e., "I' $m$ interested in lots of things") (Alpha = 0.72). Similar to the SOC scoring procedures, a high score reflected a high level of CSOC.

Studies using the CSOC explored children's personal and contextual resources and their ability to perceive family, social, and educational environments as structured and meaningful realities. The following section presents studies that used CSOC.

\section{Studies on SOC During Childhood}

A systematic search for studies on children and SOC between the years 2000 and 2019 in online databases (PsychoInfo, Ebsco, Proquest, APApsycnet, SocioFile, SAGE, Web of Science, and PubMed) using keywords (sense of coherence, salutogenesis, children, and family) and Boolean operators, presented 44 studies from 15 countries. Table 15.1 summarizes the studies.

Two major foci emerged from the review of the studies: Children's SOC within the family, school, peer group, and community environments and CSOC as a predictor of children's health and health behavior. The studies relating to CSOC and different contextual environments may be divided into three age groups/developmental stages: the preschool age stage, the elementary school-age stage, and a prolonged stage from infant to adolescence/adulthood focusing on families of children with special needs.

\section{SOC and the Child's Environments: Family, School, Peers, and Community}

The salutogenic paradigm focuses on promoting growth and adjustment. The following research deals with the contributions of children's environments: families, friends, and school systems, to the adjustment of children with typical development and children with special needs. The resilience 


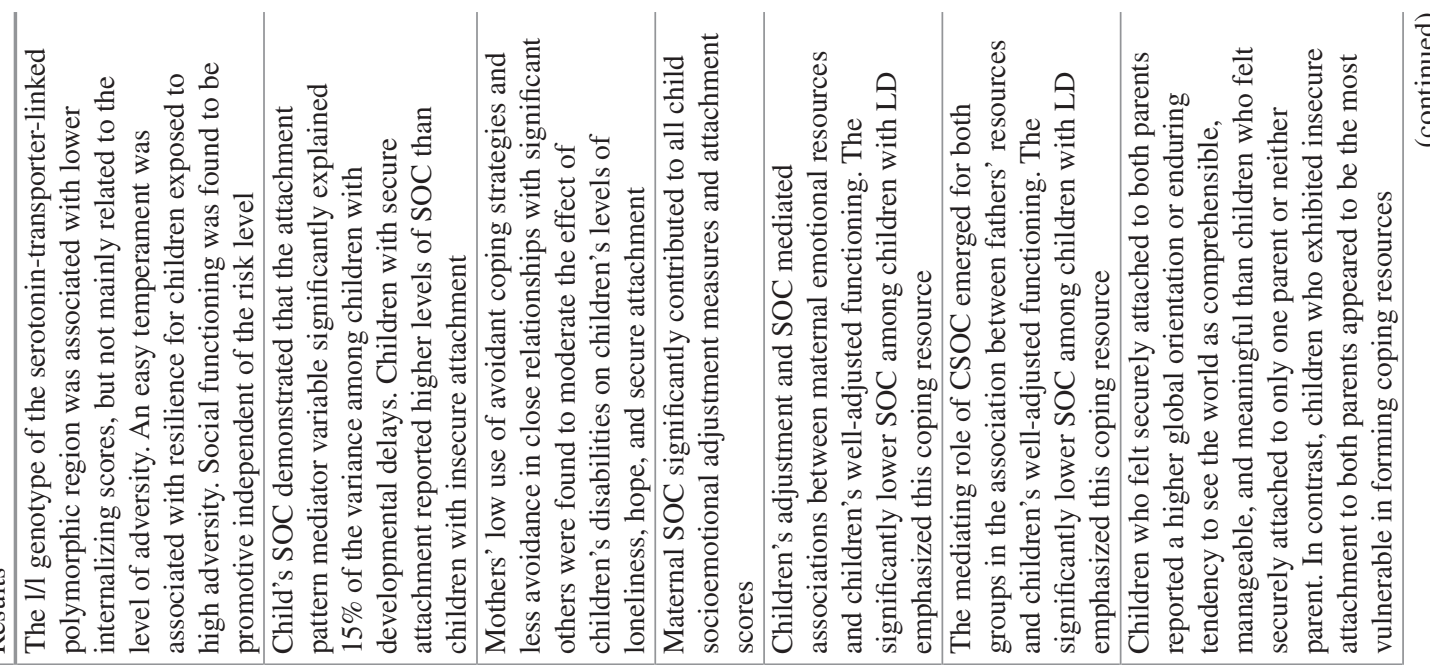

\begin{tabular}{|c|c|c|c|c|c|c|c|}
\hline & 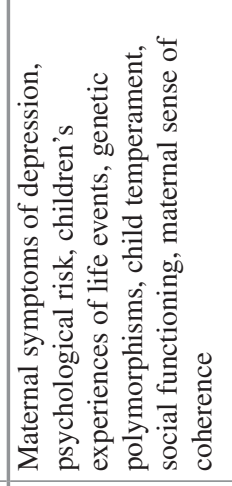 & 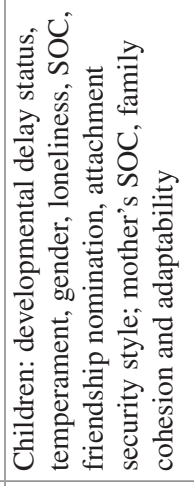 & 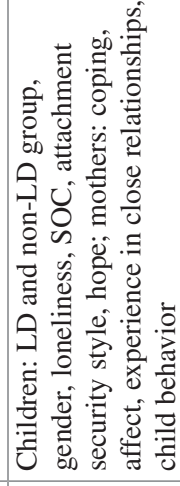 & 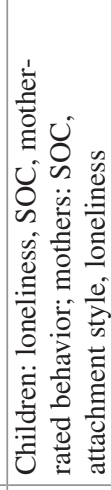 & 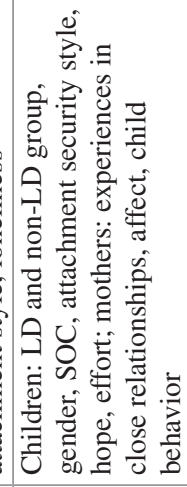 & 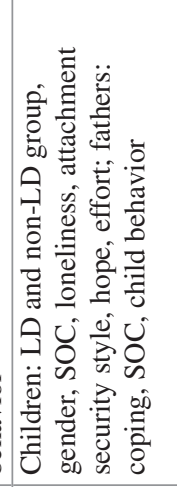 & 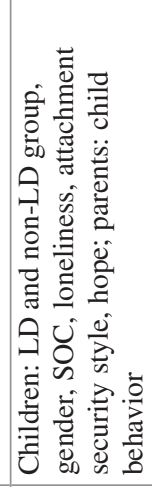 \\
\hline 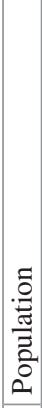 & 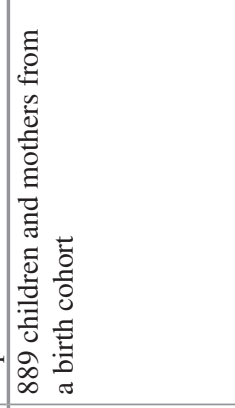 & 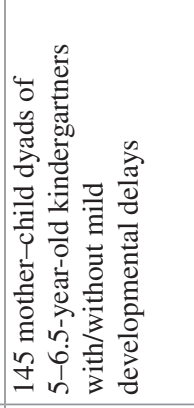 & 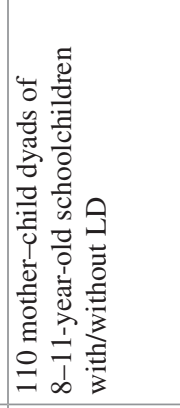 & 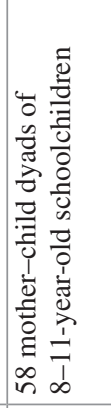 & 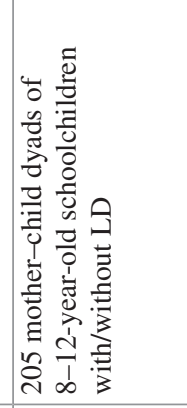 & 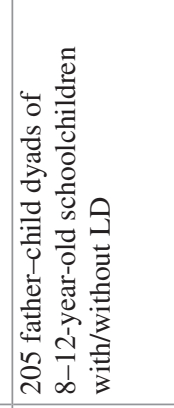 & 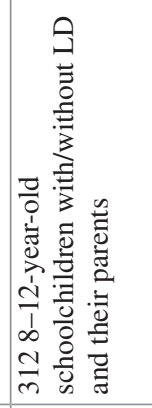 \\
\hline $\mid \begin{array}{l}\frac{\mathscr{E}}{\tilde{E}} \\
\frac{\tilde{\Omega}}{2}\end{array}$ & 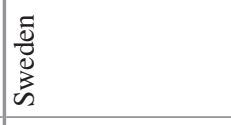 & 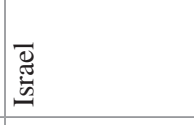 & $\begin{array}{l}\overline{\mathscr{Z}} \\
\stackrel{\mathbb{E}}{2}\end{array}$ & 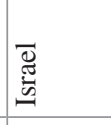 & 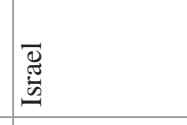 & 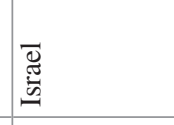 & $\begin{array}{l}\overline{\mathscr{Z}} \\
\mathbb{\mathscr { g }}\end{array}$ \\
\hline$r$ & 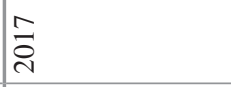 & ڤ్) & ¿্ণ & 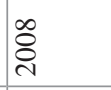 & 을 & $\overline{\vec{\nu}}$ & $\stackrel{\sim}{\stackrel{\sim}{c}}$ \\
\hline 妾 & 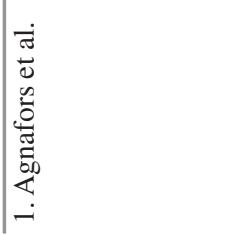 & 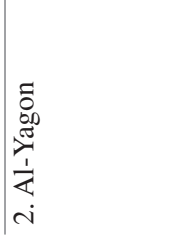 & 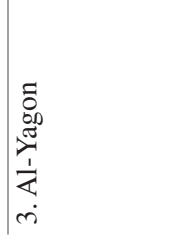 & 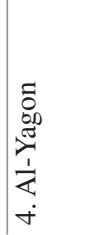 & 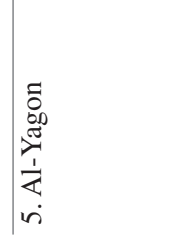 & 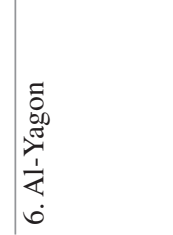 & 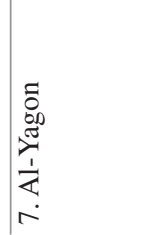 \\
\hline
\end{tabular}




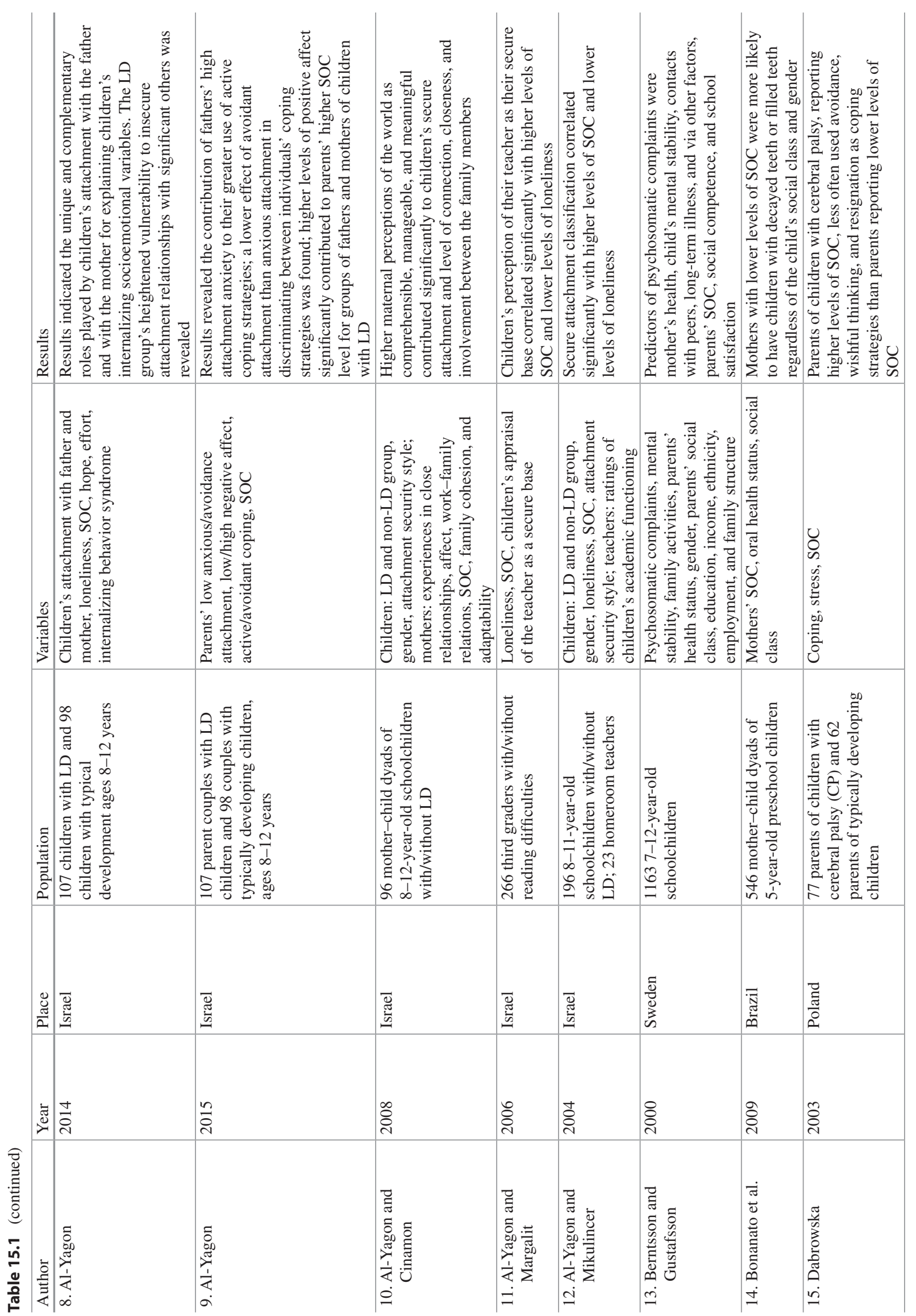




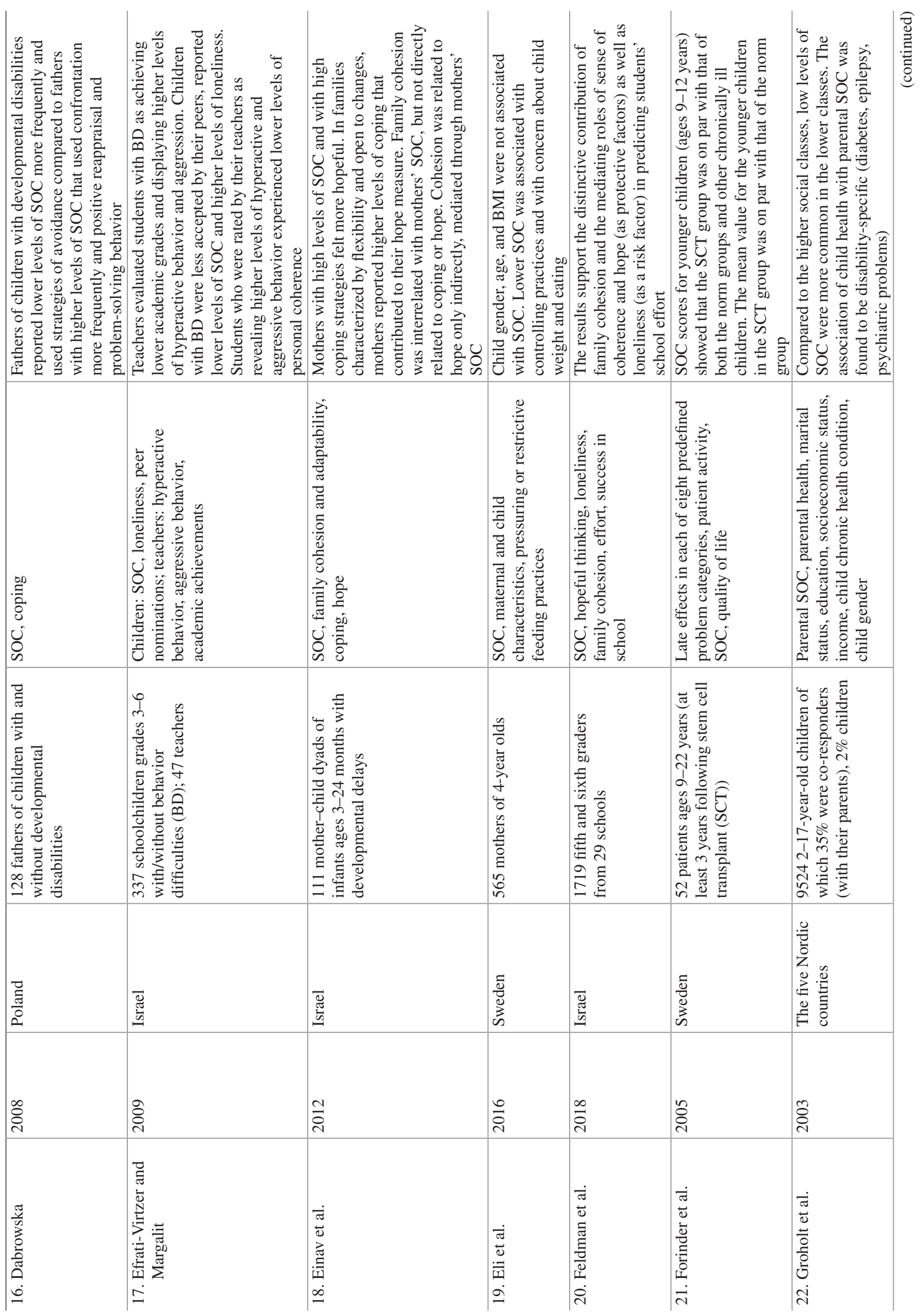




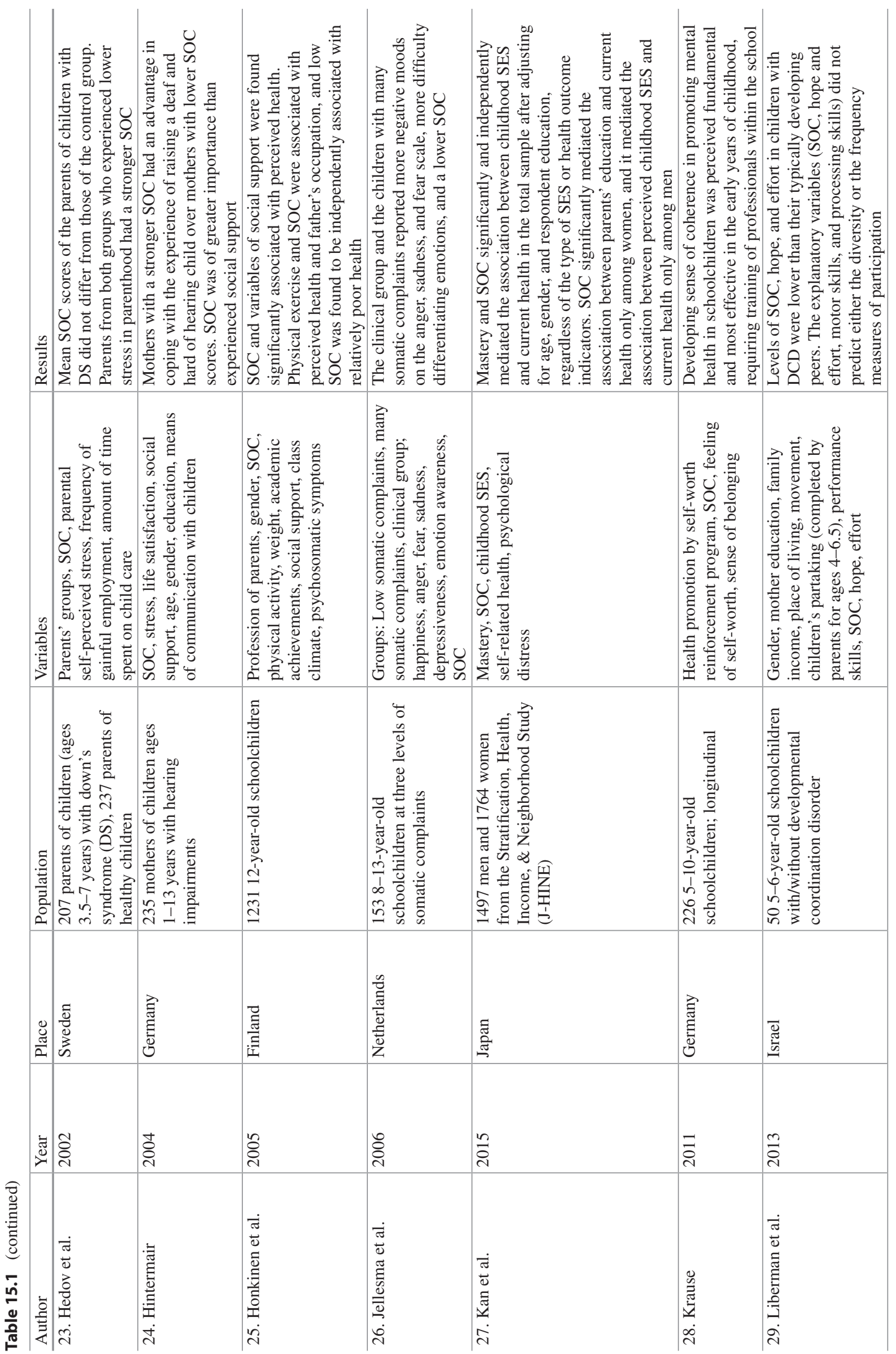




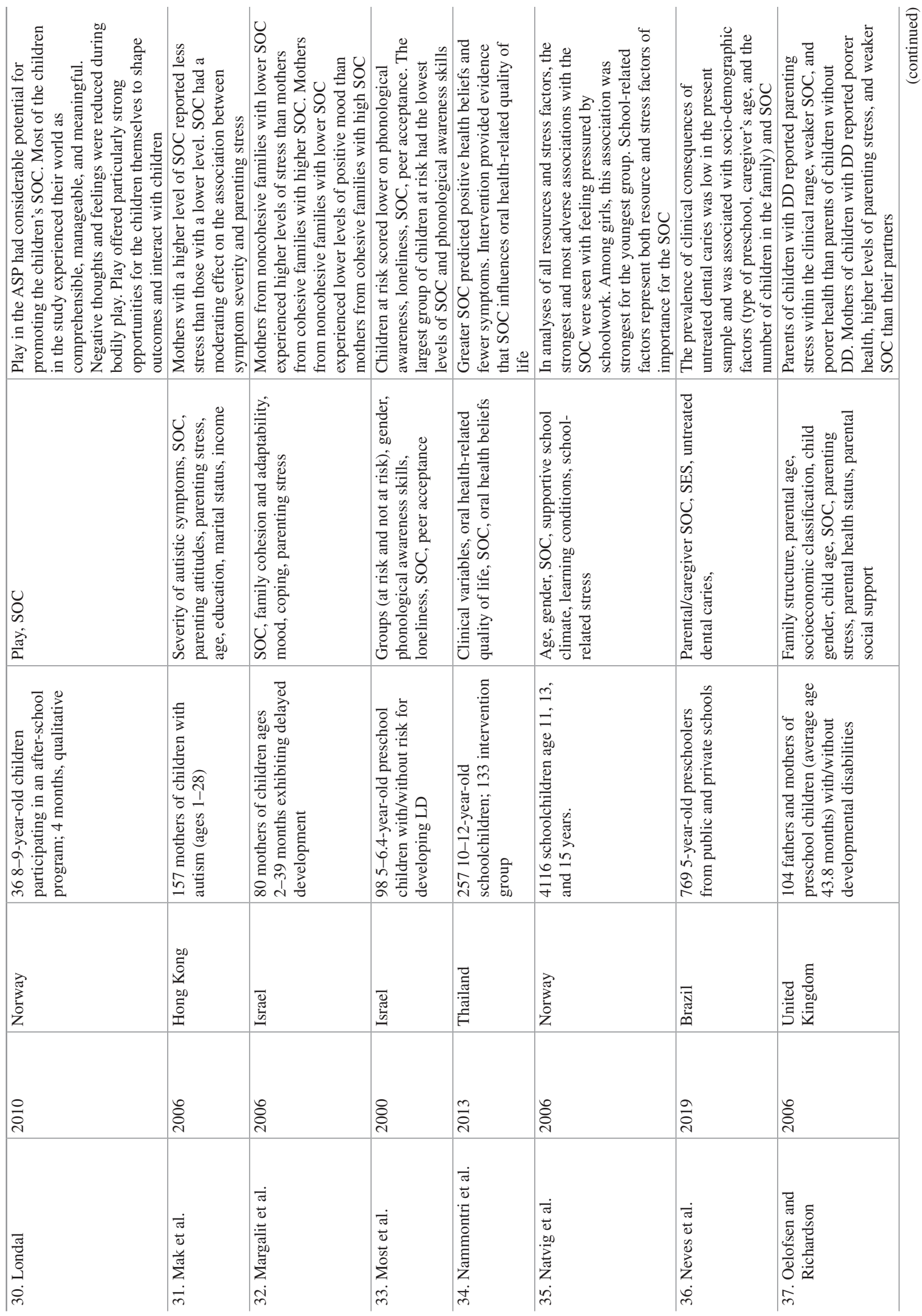




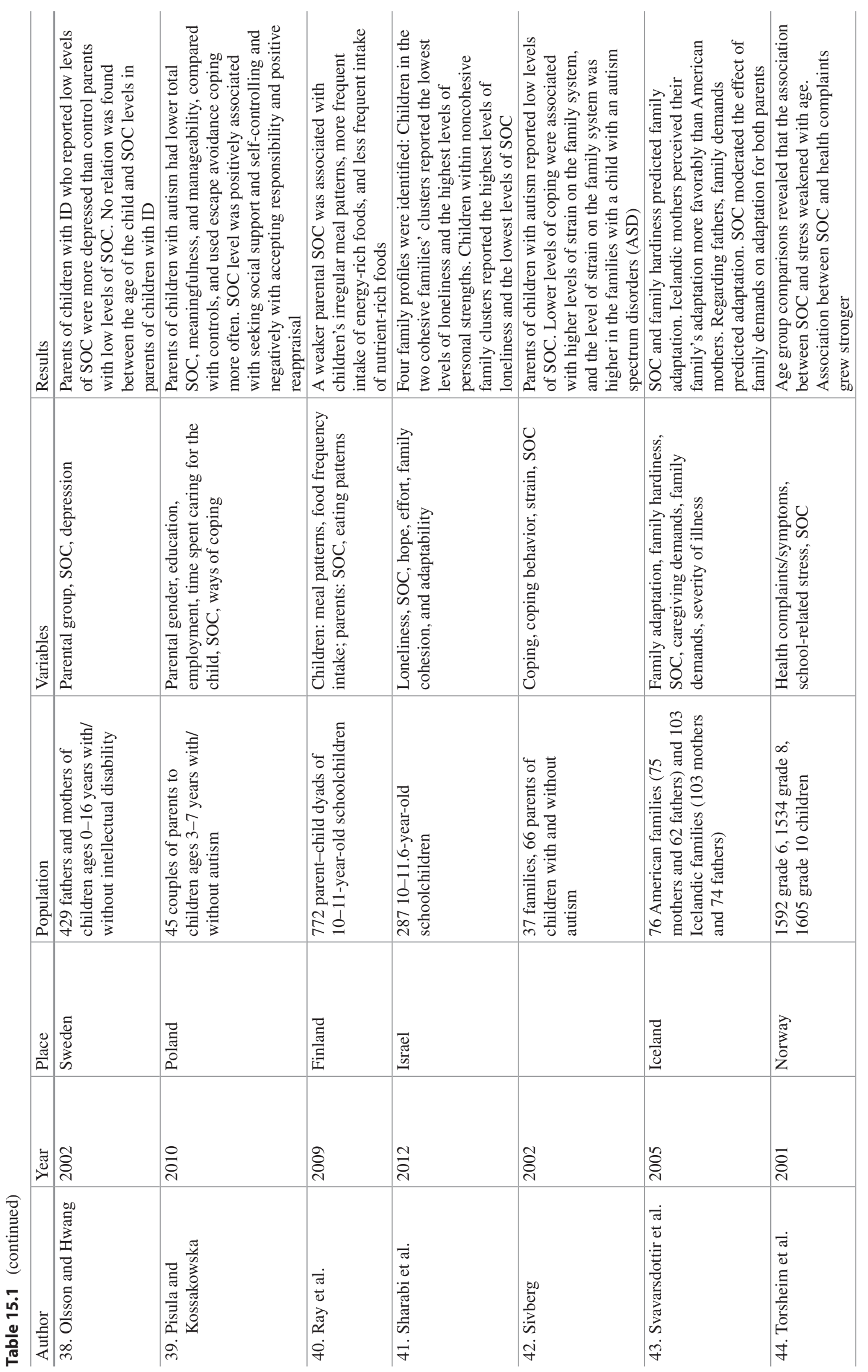


approach defines assumptions about the critical predictors of the full potential of children to learn and to thrive in diverse settings regardless of personal and environmental challenges and risk factors (Damon, 2004). A major role of resilient research is to identify the complex transactions and processes among internal and external (risk and protective) factors that affect children's resilience and sense of coherence (Margalit, 2003).

Sense of coherence at the preschool age stage Children of various ages, with a strong sense of coherence, may perceive their day-to-day experiences as comprehensible and manageable. To compare the sense of coherence of typically developing preschool children with preschool children having special needs, studies have examined children and their parents in various social contexts (Al-Yagon, 2003; Margalit, 1998; Most et al., 2000). In a sample of 187 preschool children ages 4.9-6.3 years, children who were identified as at risk for developing learning disabilities (LD), even before they were formally diagnosed and labeled, had a weaker sense of coherence, had fewer friends, and were less accepted by their peers. The sense of coherence assessment revealed the children's heterogeneity, and even among the group of typically developing children, a small subgroup could be defined with a very low sense of coherence and many social challenges. Also, in line with the salutogenic paradigm, special attention was given to a small subgroup of children within the group of children at risk whose sense of coherence was high. The relatively small extreme groups may add to the understanding of the development of coherence from early developmental stages (Margalit, 1998).

The children with a risk for developing learning disabilities received tutoring on an individual and small group basis during school time by the special education teachers. The focus was on language enrichment and basic learning skills. The sense of coherence of a subgroup of these preschool children $(N=67)$ was tested. Significant differences were noted in the comparisons between the sense of coherence scores at the beginning of the intervention and at the midyear evaluation. However, no significant differences were found between mid-year and the end of the year. The correlations between the first and the second assessments of children's sense of coherence were significant (0.34) and between the second and the third assessments (0.32) as well. It can be concluded that at this age, there was some level of flexibility in the children's sense of coherence. Remedial training on delayed academic, language, and cognitive functioning was related to an increased sense of coherence and a narrowing of the gap with the typically developing group (Margalit, 1998).

Language difficulties and social-emotional challenges are often considered as two separate risk factors at the preschool age stage. A study of preschool children explored the relations between children's sense of coherence, loneliness, and phonological awareness. Phonological awareness consists of language skills such as awareness of the structure of sounds in words and sentences. Research reports that they predict reading acquisition (Most et al., 2000). The study examined the phonological awareness skills, loneliness, sense of coherence, and peer acceptance among 98 children ages 5.0 6.4 years. Children at risk had lower achievements as a group on the phonological awareness measures, reported weaker CSOC, viewed themselves as lonelier, and were less accepted by their peers.

Family ecology is comprised of parental, familial, and environmental characteristics that may affect the capacity of the family to provide optimal care (Greenberg et al., 1993). Olson (2000) identified cohesion and adaptability as two major parameters for evaluating the functioning of a family. Cohesion refers to the extent of connection, closeness, and involvement between the family members. Adaptability reflects the family's capability to change as an adaptation to developmental and external pressures (Olson, 1986, 2000). A family system has been considered balanced when it demonstrates moderate scores on these two dimensions. In a study examining SOC, attachment security style, loneliness, and temperament of 145 children ages 5-6.5 years with and without developmental delays, and their mothers' SOC and family cohesion and adaptability, children having a secure attachment to their mothers reported a stronger SOC than children having an insecure attachment (Al-Yagon, 2003).

In summary, the studies on preschool children identified SOC as an important protective factor that differentiated children with typical development and high-risk children, even before their formal assessment and measurable academic challenges.

Sense of coherence at the elementary school-age stage The transfer to elementary schools expands the variability of the factors that affect and are affected by the children's sense of coherence. Children's academic success, social competence, and coping capabilities contribute to their well-being and adjustment during that period, while academic, social, and behavior difficulties may be considered risk factors. Interactions with teachers and peers have a profound impact on children's life quality. Multiple studies examined the relations between children's sense of coherence and their family; their perceptions of teachers' support, peer friendships, and their overall school experience, revealing the complex and multivariate interactions at the elementary school-age stage (Al-Yagon, 2007, 2008, 2010, 2011, 2012; Al-Yagon \& Cinamon, 2008; Al-Yagon \& Margalit, 2006; Al-Yagon \& Mikulincer, 2004; Efrati-Virtzer \& Margalit, 2009; Liberman et al., 2013; Sharabi et al., 2012). 
To further clarify the role of teachers in understanding children's sense of coherence, the attachment conceptualization (that was developed for children-mothers' relations) was adapted to schools' relationships. Children's perceptions of the teachers as a secure base were examined, and the results revealed that secure attachment patterns expressed in the development of close relationships with teachers predicted children's SOC and loneliness (Al-Yagon \& Margalit, 2006; Al-Yagon \& Mikulincer, 2004). Children, who felt that their teachers were more available to them and more accepting, reported a stronger SOC and less feelings of loneliness.

In another study (Efrati-Virtzer \& Margalit, 2009), the characteristics of children with behavior difficulties were examined (behavior difficulties included verbal and physical aggression toward children and objects). The age range of these children was 9-12 years, and they were compared with children with no adjustment problems from the same classes. Results revealed that the behavior difficulties contributed to the explanation of social and academic functioning and were linked to social difficulties-in terms of lower peer acceptance and increased rejection by children in their classes, as well as to lower academic achievement. Children with disruptive behavior also reported weaker levels of CSOC. Those children with stronger CSOC revealed emotional self-regulation and participated in fewer behavior conflicts at school. It is not clear whether a weaker SOC was the outcome of the multiple academic, social, and behavior difficulties or predicted them. Students with a weaker SOC were less accepted by their peers and rated as more rejected by them.

The study of social relations at school provided additional validation to the complexity of the interacting variables. The most common approach for identifying a child's status in class is done by asking the children to state the names of their best friends (and those that they do not like) as measures of social acceptance and rejection. The construct of reciprocal positive nomination (mutual friendship) attracted increased research attention since it provided information on mutual perceptions, reflecting the interpersonal attraction and liking where within a pair of children, each one selected the other as a friend (Yugar \& Shapiro, 2001). If the positive mutual nomination was an important indicator in reflecting friendship and explaining decreased alienation experience in schools, the reciprocal negative nomination (mutual selection within a dyad of children of the least liked child in the class) extended the understanding of the increased experience of social isolation, identified enemies in classes and enhanced feelings of social exclusion and loneliness. It is not surprising that they were related to a weaker SOC (EfratiVirtzer \& Margalit, 2009).

Research on elementary schoolchildren with and without developmental delays and their families identified SOC as playing a significant protective role during the first year at school. In a study on 50 schoolchildren ages 5-6 years with and without developmental coordination disorder (DCD), levels of CSOC, hope, and effort in children with DCD were lower than their typically developing peers. Significant correlations were found between CSOC to the children's involvement in daily activities in a variety of environments. The CSOC was related to the children's independence and enjoyment from participation in age-appropriate social and leisure activities (Liberman et al., 2013).

\section{The Relations Between Children's SOC and Families' Characteristics}

Several studies have shown that maternal coping resources moderated the effect of children's learning disabilities on secure attachment, levels of loneliness, feelings of hope, and future expectations. The degree to which the learning disability affected the children's socioemotional academic competence and social interrelations was related to the type of coping their mothers employed and their reliance on social support (Al-Yagon, 2007, 2008, 2010, 2011, 2012, 2014, 2015; Al-Yagon \& Cinamon, 2008): Maternal SOC significantly enhanced the child's socioemotional adjustment measures and attachment scores (Al-Yagon, 2008); children's adjustment and SOC mediated associations between maternal emotional resources and children's well-adjusted functioning. The significantly weaker SOC among children with learning disabilities (LD) emphasized this coping resource (Al-Yagon, 2010); studies also recognized the significance of children's relations not only with mothers but also with fathers. The mediating role of CSOC emerged for children with and without learning disabilities in the association between fathers' resources and children's well-adjusted functioning (Al-Yagon, 2011); children who felt securely attached to both parents reported a higher global orientation or enduring tendency to see the world as comprehensible, manageable, and meaningful than children who felt securely attached to only one parent or neither parent. In examining the differences in the role of attachment with fathers and mothers, Al-Yagon (2014) reported that in the model modified for elementary schoolchildren with severe learning disabilities (SLD), a higher number of significant paths emerged between child-mother attachment relationships and internalizing measures than for child-father attachment. Data also showed that attachment with fathers contributed mainly to children's coping resources (i.e., SOC, hope, and effort), whereas attachment with mothers contributed to a broader range of internalizing adjustment measures including not only SOC but also self-reported loneliness and parent-rated internalizing problems. In investigating the coping resources of parents of children with LD and children with typical development, Al-Yagon (2015) highlighted the potential role of parents' affect. Specifically, higher levels of positive affect 
significantly contributed to parents' stronger SOC for fathers and mothers of children with LD. However, greater negative affect contributed to greater utilization of active and avoidance coping strategist only for mothers of children with LD. Furthermore, children who exhibited insecure attachment to both parents appeared to be the most vulnerable in forming coping resources (Al-Yagon, 2012; Al-Yagon \& Cinamon, 2008).

Parents comprise only in part family cohesion. In a study on 287 schoolchildren ages 10-12 years, four family profiles were identified: children in the cohesive families' clusters reported the lowest levels of loneliness and the strongest levels of CSOC, whereas children within noncohesive family clusters reported the highest levels of loneliness and the weakest levels of CSOC (Sharabi et al., 2012). Additionally, the degree of cohesion within families was found to predict effort investment and success in school. Feldman et al. (2018) revealed that family cohesion and the mediating roles of SOC and hope (protective factors), as well as loneliness (risk factor), contributed significantly in predicting school effort among elementary school pupils.

In conclusion, during elementary school, children acquired basic learning skills, established positive and negative relations with teachers and peers, and their functioning predicted their life quality, as well as presenting special academic and behavior challenges. At this age stage, SOC was shown to provide a unique and relatively stable index of children's social and emotional adjustment and well-being. The entrance to high schools and the adolescence age stage not only provided extended opportunities but also revealed continued difficulties and new challenges. A study of the Norwegian education system explored elementary through junior high schoolchildren focusing on age and gender comparisons concerning school-related stress and resources and their relations to the SOC construct. The sample consisted of 4116 schoolchildren ages 11,13 , and 15 years. SOC was related to feeling pressured by schoolwork, social support from peers, and expectations. Among girls, this association was strongest for the youngest group. School-related factors were shown to represent both resource and stress factors related to the SOC (Natvig et al., 2006).

From infancy to adolescence/adulthood: Families of children with special needs Children with special needs are considered a source of distress to their families. Their increased levels of stress reflect their emotional reactions to the unexpected and challenging reality of having children with developmental disabilities and behavior challenges. The fathers' and mothers' SOC reflects the impacts of the prolonged stress but at the same time reveals their parental resources that may be conceptualized as resources that serve as protective factors (Margalit, 1994).
Research on infants and preschool children with developmental delays and their families (Einav et al., 2012; Hedov et al., 2002; Margalit et al., 2006; Oelofsen \& Richardson, 2006; Pisula \& Kossakowska, 2010) identified the parents' SOC as meaningful for the development of their children. In a study of 111 mother-child dyads of infants ages 3-24 months with developmental delays, mothers with strong levels of SOC and with high coping strategies felt more hopeful. The family cohesion (the mothers' perceptions that their family members were close to one another and provided support when needed) was interrelated with mothers' SOC. Cohesion was related to hopeful thinking only indirectly, mediated through mothers' SOC. Only for mothers who reported strong levels of SOC was the family support meaningful in the prediction of hopeful thinking (Einav et al., 2012).

Mothers from noncohesive families with weaker SOC experienced higher levels of stress than mothers from cohesive families with stronger SOC in a study examining SOC, family cohesion and adaptability, mood, coping, and parenting stress of 80 mothers of children ages 2-39 months exhibiting delayed development. Furthermore, mothers from noncohesive families with weaker SOC experienced lower levels of positive mood than mothers from cohesive families with a strong SOC (Margalit et al., 2006). Oelofsen and Richardson (2006), studying fathers and mothers of preschool children with developmental disabilities (DD), found that parents of children with DD reported parenting stress within the clinical range, weaker SOC, and poor health than the comparison group - parents of children without DD. The study's results focused the attention on the mothers who, as the major caregiving parent, experienced more stress than the fathers and reported more health problems, and weaker SOC than the fathers.

Studies focusing on parents to children with special needs emphasized the significance of SOC with parenting stress: parents of children with cerebral palsy, reporting a stronger SOC, less often used avoidance, wishful thinking, and resignation as coping strategies than parents reporting a weaker SOC (Dabrowska, 2003); parents of children with Down's syndrome as well as the comparison group had a stronger SOC when their stress level was lower (Hedov et al., 2002); and fathers of children with developmental disabilities reported a weaker SOC more frequently and used strategies of avoidance compared to fathers with a stronger SOC that used confrontation more frequently and positive reappraisal and problem-solving behavior (Dabrowska, 2008).

In a study on parents of children with autism, the parents reported a weaker SOC than the comparison group and used avoidance coping more often. Among parents of children with autism, the SOC level was positively associated with seeking social support and self-controlling and negatively with accepting responsibility and positive appraisal. The 
results demonstrated that the frequency of using accepting responsibility strategy increased with decreasing levels of SOC among the parents. This may suggest that one of the consequences of low SOC may be a self-blame tendency for the occurrence of stressful situations related to parenting a child with special needs (Pisula \& Kossakowska, 2010). This confirms earlier findings of a weaker SOC among parents of children with autism (Olsson \& Hwang, 2002; Sivberg, 2002).

Several studies explored SOC in families of children with developmental disorders from birth to adolescence (ages $1-13,0-16$ years) and/or adulthood (ages 1-28 years). Hintermair (2004) studied 235 mothers of children ages $1-13$ years with hearing impairments and found that mothers with stronger SOC had an advantage in coping with the experience of raising a deaf and hard of hearing child over mothers with weaker SOC scores. SOC was of greater importance than experienced social support. Similarly, Olsson and Hwang (2002) studied 429 fathers and mothers of children from birth to 16 years of age with and without intellectual disability (ID). They found that parents of children with ID who reported low levels of SOC were more depressed than control parents with low levels of SOC. No relation was found between the age of the child and the levels of SOC in parents of children with ID. In a study of children, adolescents, and young adults with autism, Mak et al. (2007) reported that mothers with a strong SOC reported less stress than those with a weak SOC. SOC had a moderating effect on the association between symptom severity and parenting stress.

In summary, the studies on families of children with special needs identified SOC as a significant protective factor related to effective coping and hopeful thinking that differentiated between families of children with typical development and families of children with special needs. Understanding the relationship between SOC and coping among parents of children with special needs provides insight into the mechanisms involved in parental adjustment and effective coping outcomes.

\section{SOC as Predictor of Health and Health Behavior}

In the past decade, research has shown the relationship between social factors, health, and disease, focusing attention on salutogenic models, concentrating on personal control. This trend followed former studies that revealed that persons with a strong SOC tended to manage stress better, whereas persons with a weak SOC tended to be more sensitive to health challenges and illness (Lundberg \& Nystrom, 1994). Recent multiple pieces of research on SOC and health have identified SOC as a predictor of health and health behavior (Berntsson \& Gustafsson, 2000; Bonanato et al., 2009; Forinder et al., 2005; Groholt et al., 2003; Honkinen et al., 2005; Jellesma et al., 2006; Kan et al., 2015; Krause, 2011; Løndal, 2010; Nammontri et al., 2013; Ray et al., 2009; Torsheim et al., 2001).

Studies examined the determinants of psychosomatic complaints in children. They found that the predictors of psychosomatic complaints were the mother's health, child's mental stability, contacts with peers, long-term illness, and, via other factors, parents' SOC, social competence, and school satisfaction (Berntsson \& Gustafsson, 2000). Furthermore, in an attempt to understand the relationship between poor perceived health during childhood and an individual's well-being throughout life, 1231 12-year-old schoolchildren in Finland were studied. SOC and variables of social support were found significantly associated with perceived health. Physical exercise and SOC were associated with perceived health and father's occupation, and weak SOC was found to be independently associated with relatively poor health (Honkinen et al., 2005). Kan et al. (2015) demonstrated the mediating role of SOC on the association between childhood economic status and health in the community adult population of Japan. SOC significantly mediated the association between parents' education and current health among women and mediated between perceived childhood socio economic status (SES) and current health among men.

Studies focusing on the relation of somatic complaints and emotional functioning of children pinpointed attention to the existence of emotional problems in children who reported somatic complaints. Jellesma et al. (2006) studied 153 schoolchildren ages 8-13 years at three levels of somatic complaints (few, many, and clinical). The results showed that the clinical group and the children with many somatic complaints reported more negative moods on the anger, sadness, and fear scale, more difficulty differentiating emotions, and a weaker SOC than the group with fewer complaints. Torsheim et al. (2001) studied 1592 sixth-grade children, 1534 eighth-grade children, and 1605 tenth-grade children in an attempt to tap the role of SOC and school-related stress as predictors of health complaints. Age group comparisons revealed that the association between SOC and stress grew weaker with age, whereas the direct association between SOC and health complaints grew stronger. Fifty-two patients aged 9-22 years, who had stem cell transplant at least 3 years before the study, participated in a study of health and quality of life. The scores obtained on SOC for younger children (ages 9-12 years) showed that children in the SCT group have a SOC level equal to that of both the norm groups and other chronically ill children. The mean value for the younger children in the SCT group was in line with that of the norm group of children age 9 (Forinder et al., 2005). 


\section{Parents' SOC and Children's Health}

The parents' role in predicting their children's health and health behavior was examined based on the salutogenic model. The relation between parental SOC and child health was explored in a large-scale study (Groholt et al., 2003) in the five Nordic countries, which included 9524 children ages 2-17 years, of which 35\% co-responded with their parents due to their young age. Compared to the higher social classes, low levels of SOC were more common in the lower socioeconomic classes. The association of child chronic health complaints with weak parental SOC was found to be disability-specific (diabetes, epilepsy, and psychiatric problems). Parents of children with diabetes, epilepsy, or psychiatric problems had 2-5 higher odds of having weak SOC compared to parents of children without a specific diagnosis.

Ray et al. (2009) studied 772 parent-child dyads of 10- to 11-year-old schoolchildren to find the relationship between food intake and parents' SOC. Weaker parental SOC was associated with children's irregular meal patterns, more frequent intake of energy-rich foods, and less frequent intake of nutrient-rich foods. Eli et al. (2016) found that mothers who had a stronger SOC were less likely to engage in pressuring or restrictive feeding practices. Resilience to stress reduced counterproductive practices, even in the presence of concern about the child's weight.

In another study, mothers with weaker levels of SOC were more likely to have children with decayed teeth or filled teeth regardless of the child's social class and gender (Bonanato et al., 2009). In contrast, the prevalence of clinical consequences of neglected dental caries was low among children attending public and private preschools in Brazil. It was associated with stronger levels of parental/caregiver SOC (Neves et al., 2019).

In a study identifying the predictors of adaptation and assessing potential moderating effects of parents' sense of coherence and family hardiness on the relationship of severity of illness of a child with asthma, SOC and family hardiness predicted family adaptation. Icelandic mothers perceived their family's adaptation more favorably than American mothers. Regarding the fathers, family demands predicted adaptation. SOC moderated the effect of family demands on adaptation for both parents (Svavarsdottir et al., 2005).

Intervention programs promoting children's health In addition to identifying SOC as a significant protective factor related to effective coping, the contribution of the salutogenic paradigm in explaining successful coping with stressors and health promotion has guided the development of intervention programs promoting health and health behavior. The following studies are examples of such intervention programs involving children and their families.
An intervention program based on the salutogenic model promoting oral health resulted in improved oral health. The intervention provided evidence that SOC influenced the oral health-related quality of life (Nammontri et al., 2013). Positive health beliefs and a stronger SOC were found to predict positive health beliefs and fewer symptoms. An additional intervention program focused on promoting play in an after-school program (ASP) had considerable potential of promoting the children's SOC. Most of the children in the study experienced their world as comprehensible, manageable, and meaningful. Negative thoughts and feelings were reduced during play. Play offered particularly strong opportunities for the children themselves to shape outcomes and interact with children, promoting their SOC (Løndal, 2010).

In another intervention program that aimed to promote health resources in children, 226 schoolchildren ages 5-10 years participated in a longitudinal self-worth reinforcement program. The results showed that developing SOC as a part of promoting mental health in schoolchildren is most effective during the early years of childhood. This finding emphasized the need to train professionals within the school (Krause, 2011).

\section{Conclusions and Future Research Directions}

The results of the surveyed studies support the conceptualization of the SOC construct as an important personal resource that develops during childhood. Stresses and challenges are a part of children's lives. However, most children who have a strong SOC can transform their potential resources into actuality, thereby promoting well-being. Children and adolescents with a strong SOC may have a good comprehension of most of their contextual conditions, situational demands, and personal experiences. They may feel relatively in control of their lives and may consider most of their tasks and participation in age-appropriate activities as meaningful, significant, and worth of investing the effort. When they face a stressful situation, they can select the appropriate strategies to cope effectively with the stressors. Thus, acquiring a wide range of coping strategies, alongside an emphasis on collaborative activities, developing social partnerships that respect different voices and self-reliance, may enhance the youngsters' resilience and motivation to invest effort to reach their preferred goals (Margalit, 1998). Consistency, a special cognitive challenge for children, may strengthen comprehensibility; an overload-underload balance, a special risk for children who struggle with school demands, may affect manageability; and the participation in socially valued decision-making may strengthen meaningfulness (Margalit, 2008).

The results of these studies have clear educational implications for school systems at various age groups in terms of 
prevention and intervention planning. The early manifestations of the developing SOC, as a personal resource, and the results that indicate that stresses and difficulties are disclosed in weaker levels of SOC, call for early awareness and empowering programs within educational systems. In addition, the results that show the impact of effective intervention not only on better academic functioning but also on friendship development and significant growth incoherence justify focused attempts on early intervention before SOC is structured and stabilized. The studies demonstrated the importance of early comprehensive intervention, as well as the significant value of preventive measures through sensitizing teachers not only to meet crises and difficulties but also especially to provide attentive support to the children's experiences. Preventive programs that empower children's abilities to integrate their thinking and learning skills with the abilities to regulate their feelings (emotion regulation) and actions (behavioral competence) promote growth, effort, and motivation (Idan \& Margalit, 2011). School-based intervention programs and teachers' training promoting salutogenic approaches in class are required, alongside family-based interventions and parents' training, to promote salutogenic approaches in the home.

In the reviewed studies, children with typical development and children with developmental disabilities, learning disabilities, and various additional adjustment challenges were included. Most children who reported higher levels of loneliness also experienced a weak sense of coherence. In several studies, the weak sense of coherence was related to children's current distress, as well as to early expressions of adjustment difficulties and family climate. Mothers' sense of coherence was found as an important personal resource that enabled successful attachment relations and was related to children's sense of coherence (Al-Yagon \& Mikulincer, 2004). Special attention was provided to groups of children with developmental or contextual challenges that reported levels of sense of coherence compatible with their typically developing peers. Thus, the awareness of the fact that difficulties never appeared in isolation, encouraged the multidimensional prevention and intervention approaches that treated not only academic or behavior challenges, but supported the whole child who had been developing satisfactory social relations while struggling with difficulties, to support coping and celebrate success and competencies. The salutogenic paradigm provides a structure to this planning, by emphasizing comprehensibility (explaining and clarifying the goals and the procedures), manageability (teaching the required skills to reach these goals), and meaningfulness (enhancing motivation and involvement in the effort).

Research presented in this review demonstrated the importance of the salutogenic approach in developmental research of children and adolescents and its potential for educational planning. The studies emphasized the interact- ing role of academic demands and social challenges with the SOC, clarifying the dynamic interactions between academic and socioemotional factors and children's readiness to treat their difficulties as challenges worthy of effort investment. These findings emphasized the major role of resilience approaches, considering SOC as a predictor in explaining well-being and adjustment, and calling for the future development of comprehensive educational intervention programs (Idan \& Margalit, 2011).

To benefit schools and children from the salutogenic approach, two future research directions are needed. First, there is a need for longitudinal studies that will document changes and stabilities in the development of CSOC. Through longitudinal studies, we can clarify the interactions between the stabilization and the flexibility of children's SOC within different contextual conditions. Second, research calls for cross-cultural comparisons of the sense of coherence development. There is a need for a coordinated international collaboration for longitudinal research to explore the interactions of SOC between cultures, families, schools, communities, and children's different growth paths.

\section{References}

Agnafors, S., Svedin, C., Oreland, L., Bladh, M., Comasco, E., \& Sydsjö, G. (2017). A biopsychosocial approach to risk and resilience on behavior in children followed from birth to age 12 . Child Psychiatry \& Human Development. 48, 584-596.

Al-Yagon, M. (2003). Children at-risk for developing learning disorders: Multiple perspectives. Journal of Learning Disabilities, 36(4), 318-335.

Al-Yagon, M. (2007). Socioemotional and behavioral adjustment among school-age children with learning disabilities: The moderating role of maternal personal resources. The Journal of Special Education, 40(4), 205-217.

Al-Yagon, M. (2008). Maternal personal resources and children's socio-emotional and behavioral adjustment. Child Psychiatry \& Human Development, 30, 283-298.

Al-Yagon, M. (2010). Maternal emotional resources and socioemotional well-being of children with and without learning disabilities. Family Relations, 59, 152-169.

Al-Yagon, M. (2011). Fathers' coping resources and children's socioemotional adjustment among children with learning disabilities. Journal of Learning Disabilities, 44(6), 491-507.

Al-Yagon, M. (2012). Subtypes of attachment security in school-age children with learning disabilities. Learning Disability Quarterly, 35(3), 170-183.

Al-Yagon, M. (2014). Child-mother and child-father attachment security: Links to internalizing adjustment among children with learning disabilities. Child Psychiatry and Human Development, 45, $119-131$.

Al-Yagon, M. (2015). Father and mothers of children with learning disabilities: Links between emotional and coping resources. Learning Disability Quarterly, 38(2), 112-128.

Al-Yagon, M., \& Cinamon, G. R. (2008). Work-family relations among mothers of children with learning disorders. European Journal of Special Needs Education, 23, 91-107.

Al-Yagon, M., \& Margalit, M. (2006). Loneliness, sense of coherence, and perception of teachers as a secure base among children with 
reading difficulties. European Journal of Special Needs Education, 21(1), 21-37.

Al-Yagon, M., \& Mikulincer, M. (2004). Socioemotional and academic adjustment among children with learning disorders: The mediational role of attachment-based factors. The Journal of Special Education, 38(2), 111-124.

Antonovsky, A. (1987). Unraveling the mystery of health. Jossey-Bass.

Berntsson, L. T., \& Gustafsson, J.-E. (2000). Determinants of psychosomatic complaints in Swedish schoolchildren aged seven to twelve years. Scandinavian Journal of Public Health, 28, 283-293.

Bonanato, K., Palva, S. M., Pordeus, I. A., Ramos-Jorge, M. L., Barbabela, D., \& Allison, P. J. (2009). Relationship between mothers' sense of coherence and oral health status of preschool children. Caries Research, 43, 103-109.

Cassidy, J. (1994). Emotion regulation: Influences of attachment relationships. In N. A. Fox (Ed.), The development of emotion regulation and dysregulation: Biological and behavioral aspects (Monographs of the Society for Research in Child Development) (Vol. 59(2-3, Serial No. 240), pp. 228-249).

Cassidy, J., \& Shaver, P. R. (Eds.). (1999). Handbook of attachment: Theory, research, and clinical applications (pp. 89-111). Guilford.

Dabrowska, A. (2003). Sense of coherence in parents of children with cerebral palsy. Psychiatria Polska, 41(2), 189-201.

Dabrowska, A. (2008). Sense of coherence and coping with stress in fathers of children with developmental disabilities. Polish Psychological Bulletin, 39(1), 29-34.

Damon, W. (2004). What is positive youth development? Annals of the American Academy of Political and Social Science, 591, 13-30.

Davidson, R. J., Lewis, M., Alloy, L. B., Amaral, D. G., Bush, G., Cohen, J., et al. (2002). Neural and behavioral substrates of mood and mood regulation. Biological Psychiatry, 52(6), 478-502.

Edwards, V. J., Holden, G. W., Felitti, V. J., \& Anda, R. F. (2003). Relationship between multiple forms of child maltreatment and adult mental health in community respondents: Results from the Adverse Childhood Experiences Study. The American Journal of Psychiatry, 160(8), 1453-1460.

Efrati-Virtzer, M., \& Margalit, M. (2009). Students' behaviour difficulties, sense of coherence and adjustment at school: Risk and protective factors. European Journal of Special Needs Education, 24(1), $59-73$.

Einav, M., Levi, U., \& Margalit, M. (2012). Mothers' coping and hope in early intervention. European Journal of Special Needs Education, 27(3), 265-279.

Eli, K., Sorjonen, K., Mokoena, L., Pietrobelli, A., Flodmark, C.-E., Faith, M. S., \& Nowicka, P. (2016). Associations between maternal sense of coherence and controlling feeding practices: The importance of resilience and support in families of preschoolers. Appetite, 105, 134-143.

Feldman, D. B., Einav, M., \& Margalit, M. (2018). Does family cohesion predict children's effort? The mediating roles of sense of coherence, hope and loneliness. The Journal of Psychology, 152(5), 276-289.

Forinder, U., Löf, C., \& Winiarski, J. (2005). Quality of life and health in children following allogeneic SCT. Bone Marrow Transplantation, 36(2), 171-176.

Greenberg, M. T., Speltz, L., \& DeKlyan, M. (1993). The role of attachment in the early development of disruptive behavior problems. Development and Psychopathology, 5, 191-213.

Groholt, E.-K., Stigum, H., Nordhagen, R., \& Kohler, L. (2003). Is parental sense of coherence associated with child health? European Journal of Public Health, 13, 195-201.

Hedov, G., Anneren, G., \& Wikblad, K. (2002). Swedish parents of children with Down's syndrome. Scandinavian Journal of Caring Science, 16, 424-430.

Hintermair, M. (2004). Sense of coherence: A relevant resource in the coping process of others of deaf and hard of hearing children? Journal of Deaf Studies and Deaf Education, 9(1), 15-26.
Honkinen, P.-L. K., Suominen, S. B., Valimaa, R. S., Helenius, H. Y., \& Rautava, P. T. (2005). Factors associated with perceived health among 12-year-old school children. Scandinavian Journal of Public Health, 33, 35-41.

Idan, O., \& Margalit, M. (2011). The salutogenic orientation: Children's sense of coherence and hopeful thinking in education of children and adolescents. TEME, Special Issue, 24(4), 5-18.

Jellesma, F. C., Rieffe, C., Terwogt, M. M., \& Kneepkens, C. M. F. (2006). Somatic complaints and health care use in children: Mood, emotion awareness and sense of coherence. Social Science \& Medicine, 63, 2640-2648.

Kan, C., Kawakami, N., \& Umeda, M. (2015). Mediating role of psychological resources on the association between childhood socioeconomic status and current health in the community adult population of Japan. International Journal of Behavior Medicine, $22,764-774$

Krause, C. (2011). Developing sense of coherence in educational contexts: Making progress in promoting mental health in children. International Review of Psychiatry, 23(6), 525-532.

Liberman, L., Ratzon, N., \& Bart, O. (2013). The profile of performance skills and emotional factors in the context of participation among young children with Developmental Coordination Disorder. Research in Developmental Disabilities, 34(1), 87-94.

Løndal, K. (2010). Children's lived experience and their sense of coherence: Bodily play in a Norwegian after-school program. Child Care in Practice, 16(4), 391-407.

Lundberg, P., \& Nystrom, F. H. (1994). Sense of coherence, social structure, and health. European Journal of Public Health, 4, 252-257.

Mak, W. W. S., Ho, A. H. Y., \& Kaw, R. W. (2007). Sense of coherence, parenting attitudes ad stress among mothers of children with autism in Hong Kong. Journal of Intellectual Disability Research, 20, 157-167.

Margalit, M. (1994). Loneliness among children with special needs: Theory, research, coping, and intervention. Springer.

Margalit, M. (1998). Loneliness and coherence among preschool children with learning disabilities. Journal of Learning Disabilities, $31(2), 173-180$.

Margalit, M. (2003). Resilience model among individuals with learning disabilities (LD): Proximal and distal influences. Learning Disabilities Research \& Practice, 18(2), 82-86.

Margalit, M. (2008). The salutogenic paradigm in education: Promoting well-being of children and their families. Paper presented at the International Seminar on Salutogenesis, Helsinki.

Margalit, M., Al-Yagon, M., \& Kleitman, T. (2006). Family subtyping and early intervention. Journal of Policy and Practice in Intellectual Disabilities, 3(1), 33-41.

Margalit, M., \& Efrati, M. (1995). Loneliness, coherence, and companionship among children with learning disorders. Educational Psychology, 16(1), 69-79.

Miller, J. G., \& Kinsbourne, M. (2012). Culture and neuroscience in developmental psychology: Contributions and challenges. Child Development Perspectives, 6(1), 35-41.

Most, T., Al-Yagon, M., Tur-Kaspa, H., \& Margalit, M. (2000). Phonological awareness, peer nominations, and social competence among preschool children at risk for developing learning disabilities. International Journal of Disability, Development \& Education, 47(1), 89-105.

Mowder, B. A., Rubinson, F., \& Yasik, A. E. (2009). Current status and future directions. In B. A. Mowder, F. Rubinson, \& A. E. Yasik (Eds.), Evidence based practice in infant and early childhood psychology (pp. 703-715). Wiley.

Nammontri, O., Robinson, P. G., \& Baker, S. R. (2013). Enhancing oral health via sense of coherence: A cluster randomized trial. Journal of Dentistry Research, 92(1), 26-31.

National Scientific Council on the Developing Child. (2004). Children's emotional development is built into the architecture of their brains. (Working paper 2). Retrieved from Center on the Developing Child website http://www.developingchild.harvard.edu 
National Scientific Council on the Developing Child. (2012). Establishing a level foundation for life: Mental health begins in early childhood. (Working paper 6). Retrieved from Center on the Developing Child website http://www.developingchild.harvard.edu

Natvig, G. K., Hanestad, B. R., \& Samdal, O. (2006). The role of the student: Salutogenic or pathogenic? International Journal of Nursing Practice, 12(5), 280-287.

Neves, E. T. B., Perazzo, M. F., Gomes, M. C., Ribeiro, I. L. A., Paiva, S. M., \& Granville-Garcia, A. F. (2019). Association between sense of coherence and untreated dental caries in preschoolers: a crosssectional study. International Dental Journal, 69, 141-149.

Oelofsen, N., \& Richardson, P. (2006). Sense of coherence and parenting stress in mothers and fathers of preschool children with developmental disability. Journal of Intellectual \& Developmental Disability, 31(1), 1-12.

Olson, D. H. (1986). Circumplex model VII: Validation studies and FACES III. Family Process, 26, 337-351.

Olson, D. H. (2000). Circumplex model of marital and family systems. Journal of Family Therapy, 22, 144-167.

Olsson, M. B., \& Hwang, C. P. (2002). Sense of coherence in parents of children with different developmental disabilities. Journal of Intellectual Disability Research, 46(7), 548-559.

Pisula, E., \& Kossakowska, Z. (2010). Sense of coherence and coping with stress among mothers and fathers of children with autism. Journal of Autism \& Developmental Disorders, 40, 1485-1494.

Ray, C., Suominen, S., \& Roos, E. (2009). The role of parent's sense of coherence in irregular meal pattern and food intake pattern of children aged 10-11 in Finland. The Journal of Epidemiology and Community Health, 63(12), 1005-1009.
Reid, J. B., Patterson, G. R., \& Snyder, J. (2002). Antisocial behavior in children and adolescents: A developmental analysis and model for intervention. American Psychological Association.

Rubin, K., Bukowski, W., \& Parker, J. (2006). Peer interactions, relationships, and groups. In W. Damon \& R. M. Lerner (Eds.), Handbook of child psychology (Vol. 3: Social, emotional, and personality development. (N. Eisenberg, Vol. Ed.), 6th ed., pp. 571-645). Wiley.

Sharabi, A., Levi, U., \& Margalit, M. (2012). Children's loneliness, sense of coherence, family climate and hope: Developmental risk and protective factors. The Journal of Psychology, 146(1-2), 61-83.

Sivberg, B. (2002). Family system and coping behaviors. Autism, 6(4), 397-409.

Svavarsdottir, E. K., Rayens, M. K., \& McCubbin, M. (2005). Predictors of adaptation in Icelandic and American families of young children with chronic asthma. Family \& Community Health, 28(4), 338-350.

Thompson, R. A. (2001). Development in the first years of life. The Future of Children, 11(1), 20-33.

Thompson, R. A., \& Lagattuta, K. (2006). Feeling and understanding: Early emotional development. In K. McCartney \& D. Phillips (Eds.), The Blackwell handbook of early childhood development (pp. 317-337). Blackwell.

Torsheim, T., Aaroe, L. E., \& Wold, B. (2001). Sense of coherence and school related stress as predictors of subjective health complaints in early adolescence: Interactive, indirect or direct relationships? Social Science \& Medicine, 53, 603-614.

Yugar, J. M., \& Shapiro, E. S. (2001). Elementary children's school friendship: A comparison of peer assessment methodologies. School Psychology Review, 30(4), 568.

Open Access This chapter is licensed under the terms of the Creative Commons Attribution 4.0 International License (http://creativecommons. org/licenses/by/4.0/), which permits use, sharing, adaptation, distribution and reproduction in any medium or format, as long as you give appropriate credit to the original author(s) and the source, provide a link to the Creative Commons license and indicate if changes were made.

The images or other third party material in this chapter are included in the chapter's Creative Commons license, unless indicated otherwise in a credit line to the material. If material is not included in the chapter's Creative Commons license and your intended use is not permitted by statutory regulation or exceeds the permitted use, you will need to obtain permission directly from the copyright holder. 